\title{
Ways of text adaptation by means of creolization in pedagogical discourse
}

\author{
Svetlana Pervukhina ${ }^{1}$ and Olga Lysova ${ }^{1^{*}}$ \\ ${ }^{1}$ Don State Technical University, Gagarina sq.1, Rostov-on-Don, 344000, Russia
}

\begin{abstract}
This research is focused on creolized or polycode texts functioning in pedagogical discourse and the ways of text adaptation by means of creolization. With the development of modern ways of communication, the number of texts combining verbal and non-verbal components has dramatically increased. In modern communication nonverbal component may be represented by pictures, photos, different printing types and colour coding, video and audio components. Due to their high efficiency such texts are used in all kinds of discourse: pedagogical, political, medical etc. One of the purposes of pedagogical discourse is the presentation of new information to students. This information should be adapted to the conceptual system of the addressee in order to facilitate the perception. Creolized or polycode texts often perform this function. According to our research, means of creolization can be used in adaptation of a notion, situational, motivational, and intensifying adaptation.
\end{abstract}

\section{Introduction}

Due to the constant development and simplification of different visualization tools and high impact on readers of creolized texts, they are being spread in pedagogical discourse. According to the research held by V. Semerjidi [1] from 60 to $82 \%$ of didactic texts contain different kinds of illustrations performing some notional part. Nowadays the interaction between a teacher and a student has changed due to the recent Covid-19 pandemic situation with its restrictions which included closure of schools, universities and other educational organizations. Face-to-face instructions has been replaced by remote teaching and learning, and blogs and websites written by professional teachers have become an indirect participants of communicative process. The overwhelming majority of these blogs, which we consider to be means of pedagogical discourse, contain different creolized or polycode texts. According to definition given by Y. Sorokin and F. Tarasov, creolized texts combine two nonhomogeneous parts: verbal and non-verbal which serve to perform one communicative task [2]. Polycode or creolized texts have become an object of many researches in linguistics. Different scientists described the nature and structure of these texts: E. Anisimova [3], E. Tarasov, Y. Sorokin, [2] M. Voroshilova,[4] S. Pervukhina [5] and others.

\footnotetext{
* Corresponding author: lysova.or@yandex.ru
} 
The aim of the article is to reveal the functions of creolized texts in process of adaptation in pedagogical discourse. According to the research they perform different functions: attracting attention to some parts of the notion, given in text, generate interest; adjusting the notion to the linguistic and conceptual framework of the recipient; help to organize the information according to conditions of communication.

\section{Materials and methods}

For the first stage of the research more than 150 creolized texts were selected from different textbooks and online resources in different areas of knowledge: Geography, Science, Mathematics, History, English etc. The principle of our selection was the combination of verbal and non-verbal components comprising one integrated text. Another principle was the presence of an educational pragmatic purpose of the text. The second stage was the content analysis of these texts. This method allowed us to reveal hybrid phenomenon of creolized and polycode texts which influences the addressee. Content analysis implied semantic analysis, conditional analysis, analysis of motives, notional fields, and personality of the addressee (age group). Classification and systematization methods helped us to classify the ways in which non-verbal components are used in the structure of creolized texts.

\section{Results}

\subsection{Pedagogical discourse}

According to V. Karasik [6] participants of the pedagogical discourse are generally a teacher and a student. So, the object of the investigation is the communication between a teacher and students by means of creolized texts. The communication is aimed to get students familiar with some new facts and notions from the world around them [7], [8], [9].

Our research material comprises didactic texts with explanation of complicated material. The major difficulties may be connected with abstract nature of knowledge. They are perceived not easily by students. There must be some methods to facilitate this process. Usually the teacher is the sender of the message (addressor) who transmits new facts comprising the system of knowledge. These facts can present new, unexpected or illogical facts for the addressee. To make these facts better consumed by the students the teacher should build them into their conceptual system. The outer word image ( $1^{\text {st }}$ signal system $)$ can become the basis of common ground for the teacher and the student. Non-verbal parts of a creolized text can serve this purpose.

Online communication gives chances for self-education [10]. It can happen in professional communication when a person gains information with practical purposes. Selfeducation is connected with a lot of obstacles. The first is lack of necessary background knowledge. It is the basis for acquiring new knowledge. The second is lack of motivation or decreasing motivation (the student starts being motivated but with the time the motivation dies away) The third is the necessity of a human communication in education. According to numerous resent research [11] efficient teacher's non-verbal communication determines student's success in teaching. Video blogs and podcasts give the opportunity to take the advantages of usage 'body language': facial expressions, gestures, body posture etc. combined with pictures or other visual tools. That is one of the reasons why podcasts and blogging are very popular in online education. 


\subsection{Creolized texts and polycode texts}

Creolized and polycode texts have heterogeneous structure. They may combine visual components, such as pictures, photos, different print types and colours, video etc. with a verbal part in order to achieve united communicative effect. Such kind of texts have been an object of the research for many scientists: U. Sorokin, E. Tarasov [2], E. Anisimova [3], M Voroshilova [4], S. Pervukhina [5], V. Chernyavskaya [12] and others. In our paper we offer to differentiate creolized texts from polycode ones. By creolized we understand texts which are used mostly in written communication, a non-verbal part of such texts can be represented by pictures, photos, different symbols, printing types and colours. The notion of polycode texts is a bit wider, they can include video, audio and visual $3 \mathrm{D}$ components together with the verbal part.

Modern communication is mostly a computer mediated communication. New computer technologies allow using different semiotic systems comprising oral and written communication, a verbal and non-verbal code in one message. There appeared a hybrid type of communication using video mode (oral communication with the video code) and a text - written verbal communication. YouTube channel, for example, offers a lot of video materials with subtitles comprising one communicative effect on an addressee. On the one hand video information is rather extensive, it gives the detailed picture of the analyzed objects but on the other hand it is important to differentiate necessary and extra details. For that purpose an additional semiotic sign should be used. It can be a non-verbal object an arrow, circle, highlighting (index symbols) or this function can be performed by verbal parts.

Another example of a polycode adapted text is a lecture with a presentation in which a lecturer's speech is an oral communication and slides are written, but together they represent one utterance. This utterance has logical cohesion because slides of the presentation represent one text connected with the oral speech of the lecturer.

Blogs on Instagram are also the example of polycode texts when they combine video or pictures together with written explanation of the topic. Thus, in one post we can find verbal, non-verbal, oral and written codes.

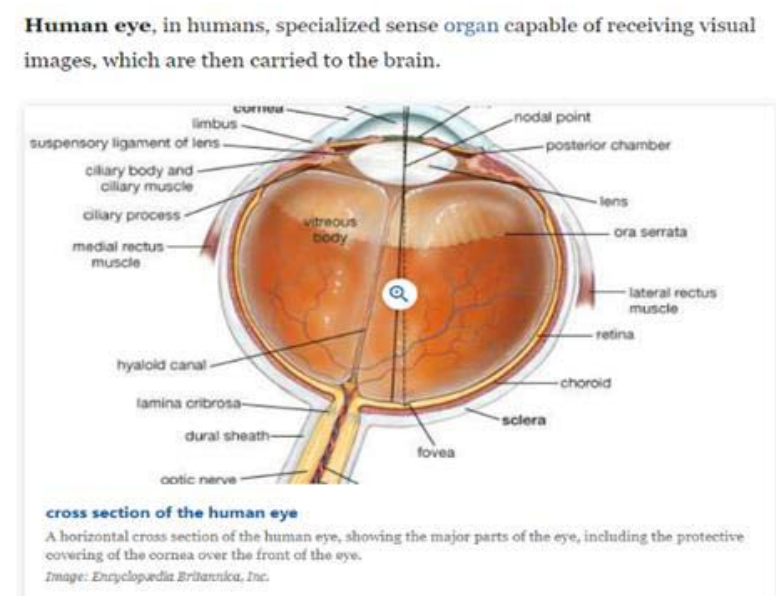

Fig.1. Coinciding of a verbal and non-verbal part (a human eye), Source: https://www.britannica.com/science/human-eye

The content analysis on its semantic and pragmatic level showed the following relations between verbal and non-verbal parts of creolized texts: coinciding, overlapping, adjoining. Coinciding is a repetition of information (Fig. 1). It happens when a picture displays a part 
of the world on its non-verbal component and the verbal part represents a nomination (or some nominations) of a non-verbal component.

A non-verbal component represents a non discrete part of a human body, that is a human eye. The verbal part of this text are nominations of areas of a human eye that are important for a specialist or a student of a medical university. These notions make the image discrete dividing it into sections or parts of that organ: sclera, lens, medial rectus muscle etc.

Overlapping is a partial repetition of information of a non-verbal component by words. In this relation we've got some extra information in either a verbal or non-verbal component (Fig.2)

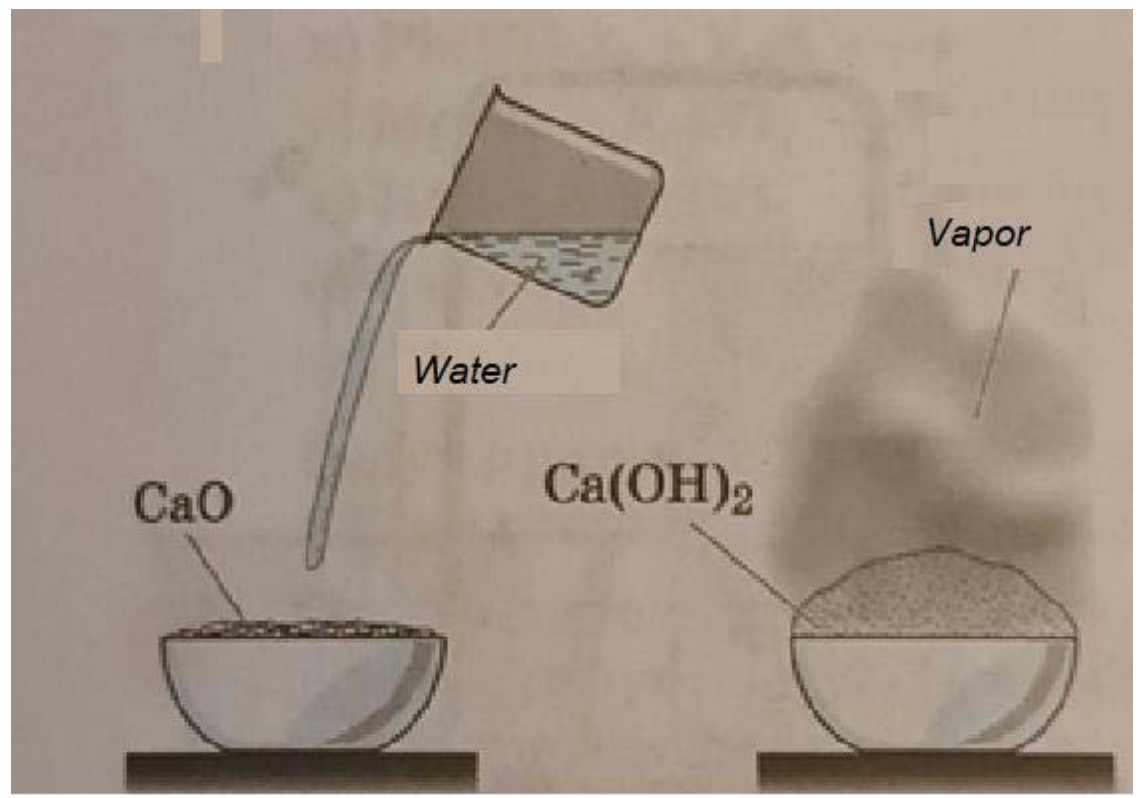

Fig. 2. An example of overlapping of a verbal and non-verbal component of a creolized text. (Interaction of calcium oxide with water)

In this example we can see a verbal nomination of a chemical reaction. The picture shows two stages of this reaction. It also shows the exact stages of how this reaction should be done: some water from a beaker is added into a bowl with calcium oxide. The second picture shows the result of such a reaction: multiplied powder and a vapour. Thus, a nonverbal component shows some extra details (a beaker, a bowl, vapour) that create visualization of the situation of communication.

Adjoining is a repetition of a topic, that is touched upon by a verbal component and illustrated by a non-verbal component (Fig.3) 


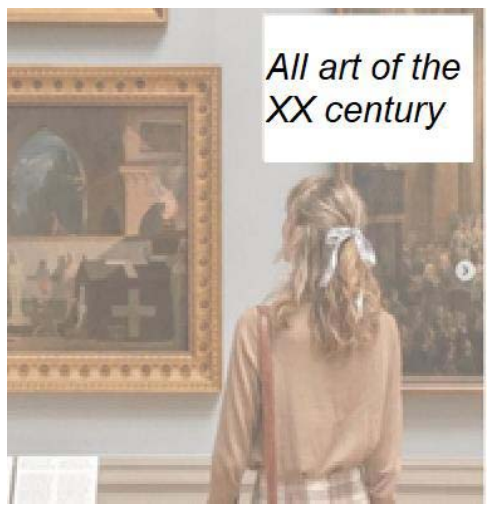

Fig. 3. An example of touching, Source: https://www.instagram.com/p/CKgCrymlFbd/

In Fig. 3 a verbal component - "All painting of the $19^{\text {th }}$ century" opens the topic of the text. The non-verbal component depicts two paintings as an example and the lady admiring these paintings. It creates the situation of communication but not exactly the topic. The topic is only touched upon.

\subsection{Criteria of textuality}

As polycode and creolized texts represent complex heterogeneous structure they should correspond to the several criteria to be referred as single text. According to R. Beaugrande and W. Dressler [13] there are seven main criteria of textuality: cohesion, coherence, intentionality, situationality, acceptability, intertextuality and informativity. All these criteria can be found in creolized texts. The verbal part shows cohesion and coherence. The non-verbal parts are usually situationally connected with the verbal parts, both parts render information. The creolized texts are aimed at their readers, their perception, comprehension and interpretation of the texts.

\subsection{Adaptation}

We see adaptation as a strategy of text transformation. The term was defined as a specific text transformation that adjusts it to a new situation of communication where a new reader with different background knowledge or reading conditions can not fully and completely understand the source text [5]. Under these new reading conditions, it is necessary to transform the text so that it will have new vocabulary, syntactic structures, extra information or abridged text rendering. Such text transformations are widely exploited in professional, legal, medical discourses [5]. The vocabulary and syntactic structures should be familiar to the reader, so that the language of the text will not be an obstacle for understanding [Engberg]. The language of the text is not the only one difficulty in understanding. Sometimes the very information of the text can be too novel or weird for the reader. Moreover, it can contradict some of the previous knowledge, or do not agree with what is taken as the truth. In this case, it is important for an adaptor of the text to design a new image of the world for a reader [15].

So, there is a question of how to build a new system of knowledge and to fill in the blanks of the reader's knowledge. There are two means of presenting information that are used for text adaptation. These are verbal and non-verbal semiotic systems, and their different combinations. Usage of polycode (non-verbal and verbal systems together) is of great interest for linguists nowadays [16], [17], [18]. The reasons of such popularity are the 
following. The verbal code is good for description of abstract things, but it is approximate, and it causes misunderstanding due to personal world image and personal presuppositions. Communication barriers were studied by V. Demchenko[19]. The question of approximation of a natural language has become axiomatic in linguistics. Anyway, people understand each other due to some similar notions, shared experience and language and text redundancy. Making use of a new semiotic system may be a good method how to find a common ground in explanations. This question will be surveyed further.

\subsubsection{Primary and Secondary texts}

It should be highlighted that an adapted text is always a secondary text. The primary text is known to be the text that reflects the world itself, its objects, ideas, situations etc. The secondary text reflects the text which in its turn reflects the world. That means that the secondary text is based not on the objects (ideas, situations etc.) of the world (Fig.4) but the primary text. Sometimes there is a necessity to construct the secondary text because it is based on the message (a primary text) that is not comprehensible for some reason. These reasons may be the age of the addressee, level of basic and background knowledge, time limits. Thus, the secondary adapted text is the product of text transcoding that helps to solve such problems of text comprehension.

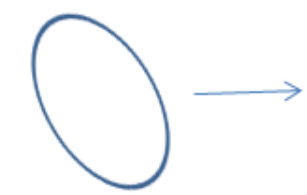

The world

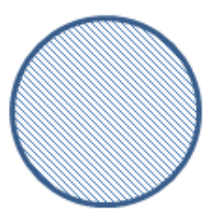

The primary text

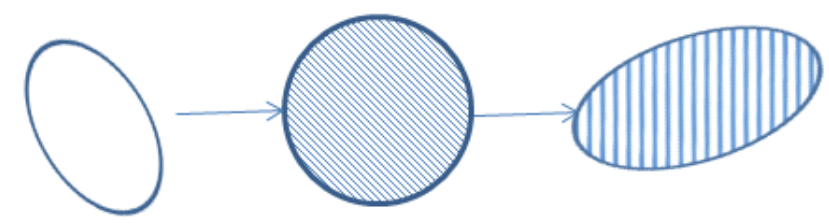

The world

The primary text

The secondary text

Fig.4 Scheme of reflection of the world by primary and secondary texts

Fig.4 displays that the secondary text does not reflect the world itself. It reflects it via the primary text. It has got some features of the fragment of the world and some features of the primary text.

\subsection{Ways of adaptation}

Our material shows that there are different functions of components of a creolized or polycode text. These functions reflect different ways of adaptation of a creolized text. They are the following: motivational, situational, intensifying adaptation and adaptation of a notion. 


\subsubsection{Motivational adaptation}

Attractive function of creolized texts seems to be very important in pedagogical discourse. According to numerous researches: C. Painter, J. R. Martin, L. Unsworth [20], A. Esposito [21], S. Pervukhina, [5] and others, a visual channel of perception dominates the rest channels. Polycode and creolized texts facilitate the perception of the utterance, applying to the second signal system. Reader's interest is rising due to the usage of the variety components of creolization: colours, pictures, photos, printing types, diagrams and schemes in creolized texts and video or audio component in polycode ones. Having analyzed more than 150 creolized and polycode texs, we came to the conclusion that the overwhelming majority of creolized texts (98\%) contains motivational component (Fig. 5), which is able to combine with others. Visualization of information in texts belonging to pedagogical discourse generates students interest, increases their motivation. Situational adaptation is found in $38 \%$ of texts and most of them belong to different means of online communication. About $56 \%$ of creolized texts reveal the adaptation of a notion: different pictures and photos reinforce the notion or represent its visual image to the addressee. The average number of examples of intensifying adaptation is about $23 \%$. These are diagrams, schemes and pictures with verbal signs describing discrete components of the notion.

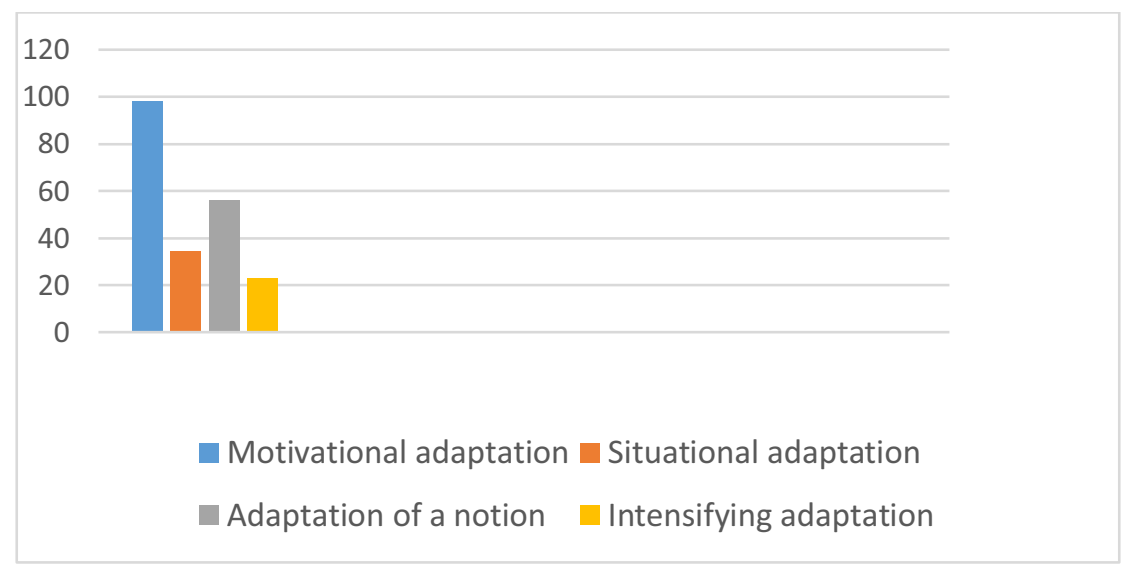

Fig. 5. Frequency of usage of different ways of text adaptation by means of creolization.

\subsubsection{Adaptation of a notion}

One of the aims of pedagogical discourse is to explain notions about different areas of science which seems to be very complicated task without adjusting an explanation to sphere of concepts of an addressee. In most cases the notion is simplified or divided into several parts which can be easily interpreted. For example, most books and online resources represent the notion of 'the water cycle' (Fig.6) as a creolized text, with the picture of a cycle inside which readers can find all the parts of this process or just a simplified variant, it depends on the age group of the recipient. Verbal component can be represented by such notions as 'precipitation', 'evaporation', 'condensation' or simple notions like 'sun', 'cloud', 'rain'. Thus, the natural phenomenon is given in accordance with the addressee's sphere of concepts and the notion is simplified, made more 'visual' and can be easily understood. 


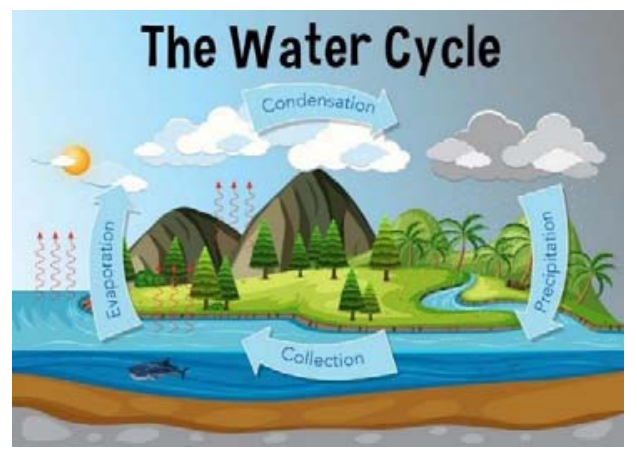

Fig. 6. The example of adaptation of a notion 'the water cycle'

\subsubsection{Situational adaptation}

Modern tendency for constant self-education and long pandemic period aroused the necessity in rapid development of digital devices and tools for distant learning [22]. Educational process within online communication has changed general tendency according to subsequent learners' demand on immediately applicable skills and information given in a shortest possible time, and text combining verbal and non-verbal components give great opportunity to percept this information without any dependence on place, time or other factors. So, in blogs and other online didactic resources the information is adapted to meet all this challenges of modern communication. The addressee acquires an opportunity to learn whenever he is ready to do that. By situational adaptation we understand the segmentation of information into small pieces which can be easily perceived and integrated in everyday life of an addressee. There are many blogs which help people who would like to improve some skills in different foreign languages. Usually one post of a blog represents a brief explanation of some grammar rule, lexical items or even useful sentences. In Fig.7 we can see the example of a polycode text, which consists of a verbal component (inscriptions) and video. In this video the teacher reveals one of the meanings of the polysemantic adjective 'funny'. Video component sets the context, and verbal is represented by inscriptions: the equal sign with the synonym and sentences which describe the video and serve as the example of a possible communicative act. This text was created in order to make a short learning activity. According to our dates the situational adaptation is used frequently in online communication and less often in written textbooks.
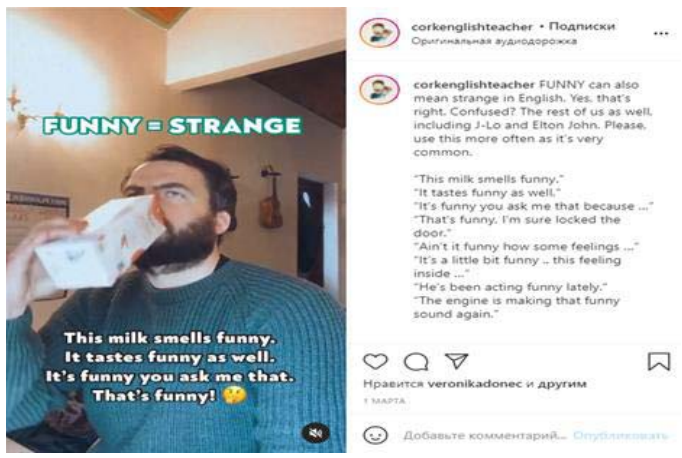

Fig. 7. The example of situational adaptation, Source: https://www.instagram.com/p/CL4fn8enW0m/ 


\subsubsection{Intensifying adaptation}

Usually intensifying adaptation is represented by different schemes and diagrams and may be found in such areas of science as biology, chemistry, physics etc. when it is necessary to represent a notion which has a complicated structure. For instance, the article from Encyclopedia Britannica explains the notion 'order of architecture' in context of styles of classical architecture. According to this style there were five types of the form of the capital. The picture (Fig.8) represents visual image of the capitals and verbal - the nomination. So, visualization in this case adds new details to the text, which help readers to comprehend and memorize the information from the article.

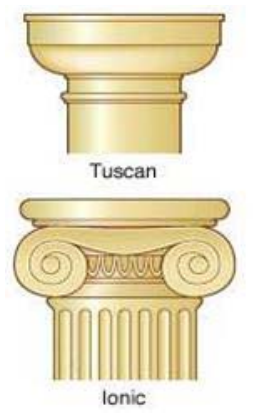

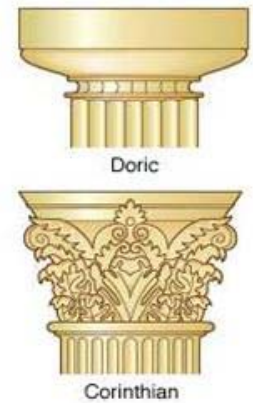

Fig. 8. The example of creolized text with intensifying adaptation, Source:

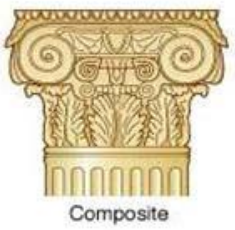

(9) 2006 Merriam-Webster, Ino https://www.britannica.com/art/Classical-architecture

\section{Conclusion}

The material of our research shows that creolized texts are very useful for educational purposes. First of all, they have got a strong motivational component, they attract the readers' attention and reflect the world image as it is. They also emphasize the important details of the notion or a researched object. We have found out that they are easier to understand and they are quicker to be understood due to the ability of our sight to perceive a complete picture of researched objects. Still further research is needed to explore the methods of their creation. These texts are sure to gain the researchers' attention because they are very widely spread and applicable.

Adaptation strategies are in great demand in pedagogical discourse. The learning styles and learning strategies are individual, and teachers or educators need to find universal strategies to make their messages comprehensible for a wide readership.

Adaptation strategies also find their place in professional discourse because they present such a strategy of text transcoding that meets the requirements of the learner under various complicated conditions (lack of direct communication with the teacher, lack of background knowledge, lack of motivation for studies). Adaptation by means of creolization is a promising strategy of text transcoding in computer-mediated educational and professional communication.

\section{References}

1. V. Semergidi, Proceedings of Voronez State University. Series: Linguistics and intercultural communication. 1, 146-149, (2014)

2. U. Sorokin, E. Tarasov. Optimization of verbal impact, 180-186, (1990) 
3. E. Anisimova, Texts linguistics and intercultural communication (based on creolized texts) (2003)

4. M. Voroshilova, Political creolized text: keys to understanding (2013)

5. S. Pervukhina, Humanitarian researches, 2, 59, 7-10, (2015)

6. V.Karasik, Language circle: personality, concepts, discourse (2002)

7. T.Mikheeva, E. Murugova, Y. Morozova, V. Demchenko. Training as a major tool of teacher professionalism enhancement. INTED2020 Proceedings 14th International Technology, Education and Development Conference 1211-1215 (2020) doi: 10.21125/inted.2020.0417

8. E.E. Sakharova, N.P. Revyakina. SHS Web of Conferences (ITNO- 2020) DOI: https://doi.org/10.1051/e3sconf/20202101804 (2020)

9. E.Egorova, N. Bulankina, O. Mishutina, V. Tsybaneva, Features of pedagogical design of a digital language course for the university students - INTED2021 Proceedings, (2021) doi: 10.21125/inted.2021.0159

10. E.V. Murugova, T. B. Mikheeva, Validation of Non-Formal Learning in Russia: New Challenges. E3S Web of Conferences 210, 18095 (2020) doi: https://doi.org/10.1051/e3sconf/202021018095

11. A. Wahyuni, Advances in Social Science, Education and Humanities Research (ASSEHR), 1st International Conference on Intellectuals' Global Responsibility, 125, 80-83, (2017)

12. V. Chernyavskaya, Vestnik Irkutskogo Gosudarstvennogo Lingvisticheskogo universiteta, 2, 23, 123-127 (2013)

13. De R. Beaugrande, W. Dressler, Introduction to Text Linguistics (Longmann, London, 1981)

14. J.Engberg, Journal of Pragmatics, 42.1, 48-63, (2010) doi:10.1016/j.pragma.2009.05.011,

15. Y. Man, Procedia Computer Science, 31, 663-670 (2014)

16. J. Bateman, L. Thiele, H.Akin, Journal of Pragmatics, 175,112-128, (2021)

17. I.Vashunina, A.Nistratov, E.Tarasov, Polylinguality and Transcultural Practices, 16.4, 472-484, (2019) DOI:10.22363/2618-897X-2019-16-4-472-484

18. S.Dmitrichenkova, E. Dolzhich, Procedia Computer Science, 103, 584-588. (2017) doi:10.1016/j.procs.2017.01.071

19. V. Demchenko, I. Khoroshevskaya, K. Krukov Communication Barriers of a Construction Company's Network Management International Science and Engineering 1079, 032089 (2021)

20. C. Painter, R.Martin, J. Unsworth. Reading Visual Narratives, (2014)

21. A. Esposito. Cognitive Computation, 1.3, 268-278, (2009) DOI:10.1007/s12559-0099017-8

22. S.A. Gill, S.D. Irwin, R. Yuk-kwan, et al, 2020 IEEE International Conference on Teaching, Assessment, and Learning for Engineering (TALE), (2020) DOI: 10.1109/TALE48869.2020.9368322 